\title{
PERFIL DE TUTOR DE CURSOS PELA INTERNET: O CASO DO SEBRAE
}

\author{
PROFILE OF THE TUTOR OF \\ INTERNET COURSES OF SEBRAE \\ LE PROFILE DU TUTEUR DES COURS PAR \\ L'INTERNET OFFERTS PAR SEBRAE \\ PERFIL DE TUTOR DE CURSOS POR LA INTERNET: \\ EL CASO DEL SEBRAE
}

Vani Moreira Kenski *

\section{RESUMO}

Este texto relata alguns momentos da pesquisa feita com os tutores que atuam nos cursos via Internet do Sebrae. No primeiro momento da pesquisa foram definidos o perfil do tutor e as suas competências, a partir de levantamentos teóricos e seguidas consultas a profissionais que atuam na coordenação e nas tutorias dos cursos on-line do Sebrae. Em seguida, foi produzido um documento com os resultados desse levantamento. Esse documento foi distribuido e analisado pela totalidade dos tutores que atuam nos quatro cursos on-line oferecidos pelo Sebrae. A partir da análise das respostas dos tutores foi proposto um modelo de formação continuada de tutores para atuação em cursos on-line.

Palavras-chave: Sebrae. EAD. Cursos on-line. Tutor. Competências. Formação continuada.

* Doutora em Educação pela Universidade Estadual de Campinas (Unicamp, 1990). Professora do Programa de Pós-Graduação em Educação da Universidade de São Paulo (USP). Diretora da "Site Educacional Ltda.”. Consultora do Sebrae. Pesquisadora do CNPq (vani@siteeducacional.com.br). 


\section{INTRODUÇÃO}

O Sebrael $\mathrm{Na}$, em uma iniciativa pioneira, oferece cinco cursos pela Internet, gratuitos e de curta duração, para empreendedores e interessados em criar o seu próprio negócio. Esses cursos são orientados por tutores, escolhidos entre os profissionais experientes que atuam como instrutores em cursos presenciais nos diversos Sebraes, localizados em todo o Brasil. Para iniciar as atividades de tutoria, os profissionais selecionados realizam cursos específicos para atuação a distância. Articulados em rede, os tutores recebem orientações e acompanhamento permanente, participam de encontros, congressos e de cursos de atualização.

Visando melhorar ainda mais a qualidade do desempenho desses tutores, o SebraelNa preocupou-se em definir o perfil de competências desses profissionais. Considerou-se, para o início desta pesquisa, que o avanço tecnológico e a fluência digital dos alunos exigem permanente atualização de todos os profissionais que atuam em educação, sobretudo os que realizam interaçõos e mediações via Internet. Considerou-se também que as especificidades dos projetos realizados a distância pelo SebraelNa precisam da definição clara de conhecimentos, habilidades e atitudes que se configuram como competências necessárias ao desempenho dos tutores de seus cursos a distância via Internet.

Em termos operacionais, essas competências têm múltiplas finalidades. A primeira delas é a possibilidade de organização de programas de capacitação continuada para os tutores, de acordo com as suas necessidades de atuação em projetos de cursos a distância via Internet. Além disso, elas permitem a definição de parâmetros básicos para a avaliação de desempenho dos tutores em atividade e para a contratação de novos tutores, para os próximos cursos a distância da organização.

A pesquisa foi realizada em três momentos. O primeiro momento foi orientado para a definição do perfil profissional do tutor dos cursos a distância via Internet do SebraelNa. Dividido em cinco fases, esse momento de pesquisa iniciou-se com o levantamento das competências essenciais de tutoria on-line disponíveis na literatura e em experiências semelhantes e padrões aceitos internacionalmente. Ao mesmo tempo, foram realizadas a leitura e a análise da documentação do Sebrael $\mathrm{Na}$ referente à criação, desenvolvimento e manutenção dos cursos pela Internet e das normas para contratação e desempenho dos profissionais-tutores. Foram identificadas as funçōes e ações dos tutores já levantadas nos documentos oficiais do SebraelNa. Os resultados encontrados no "perfil teórico do tutor de cursos a distância on-line" (fase 1) foram compatibilizados com os apresentados nos documentos oficiais (fase 2).

A pesquisa objetivou a definição de competências dos tutores não apenas referentes aos seus desempenhos nos cursos a distância já existentes, mas como esses profissionais vão poder atuar, em nível de excelência, nas futuras demandas educacionais oferecidas com as mais novas tecnologias. Essa preocupação levou-me a entrevistar alguns dos membros 
da coordenação dos cursos pela Internet do Sebrael $\mathrm{Na}$, sobre a situação atual do processo de tutoria e suas expectativas. Com os dados obtidos, foi elaborado um primeiro rol de competências, que se configurou como o "perfil operacional do tutor" (fase 3). Concluída essa fase, o perfil dos tutores foi discutido e reconfigurado por um grupo de 3 (três) tutores Master designados pelo SebraelNa. Todas as categorias e competências foram analisadas pelos três tutores, reunidos em um fórum específico, on-line, com a pesquisadora.

Essas discussōes culminaram com a validação de um corpo definido de categorias e competências, relacionadas com o desempenho em nível de excelência dos tutores dos cursos a distância do Sebrael $\mathrm{Na}$, de acordo com os encaminhamentos dos referenciais educacionais e da vivência dos tutores nesses cursos (fase 4). A última fase deste primeiro momento de pesquisa foi dedicada à análise das diversas contribuições recebidas e organização do perfil operacional dos tutores de cursos via Internet do SebraelNa. Esse perfil serviu de base também para a elaboração de instrumentos para a análise do desempenho nessas competências (dois questionários e um roteiro de entrevistas) por todos os tutores em exercício, objeto das ações do segundo momento da pesquisa.

Os instrumentos criados possibilitaram a análise geral do desempenho dos tutores em atividade nos cursos via Internet, a identificação de possíveis desvios no perfil construído e a elaboração de proposta para capacitação contínua dos tutores, inclusive os que possam vir a ser contratados para novos cursos a distância oferecidos pelo SebraelNa.

Participaram desta avaliação todos os tutores em exercício (10 Tutores Máster - TM e 114 tutores). Todos responderam a questionários sobre os seus desempenhos (no caso dos TM, eles responderam sobre seus próprios desempenhos e sobre o desempenho dos tutores sob sua coordenação), de acordo com o perfil construído na pesquisa anterior.

Para garantir maior fidelidade ao processo de pesquisa, foram entrevistados ainda oito profissionais (quatro TM e quatro tutores), dois de cada um dos cursos oferecidos pelo SebraelNa via Internet. Nessas entrevistas foram levantadas especificidades de cada um dos cursos e que originam algumas necessidades diferenciadas de atuação e formação dos tutores.

Os dados coletados nas respostas dos tutores deram origem a gráficos, quadros e tabelas, em que foram apresentados índices sobre seus desempenhos e opiniões em relação às suas atividades profissionais. A análise desses dados permitiu a elaboração de quadro geral com o desempenho dos tutores, seus pontos fortes de atuação e aspectos que possam ser aperfeiçoados. A partir dessa análise foi desenvolvida uma proposta para capacitação, atualização e formação de tutores, de acordo com os aspectos identificados na pesquisa.

Este texto tem como objetivo a apresentação dos resultados obtidos no primeiro momento do estudo realizado. A pouca literatura existente, sobretudo em Língua Portuguesa, sobre as competências dos profissionais que atuam como tutores, em projetos de educação a distância via Internet, reforça a importância da divulgação do processo 
desencadeado por este estudo e os resultados alcançados. É preciso reforçar, no entanto, que os dados aqui obtidos estão diretamente vinculados com as especificidades do projeto educacional do SebraelNa para educação a distância via Internet. Neste sentido, ainda que possam auxiliar como referência inicial, não devem ser generalizados.

A qualidade de projetos educacionais está vinculada à total articulação entre os princípios e objetivos para os quais foram desenvolvidos e a atuação de todos os profissionais em consonância com a proposta pedagógica daí desencadeada. Neste sentido, o estudo se apresenta como mais uma contribuição para garantir o nível de qualidade e excelência do projeto educacional desenvolvido a distância via Internet pelo SebraelNa.

\section{DEFINIÇÃO DE COMPETÊNCIAS PROFISSIONAIS DO TUTOR DO SEBRAEINA}

A elaboração do perfil profissional dos tutores de cursos a distância do SebraelNa foi realizada em um processo progressivo de estudos e contextualizações cujo ponto de partida foi a definição de competências que delimitem os pontos básicos e estruturais de atuação desses profissionais. O perfil profissional, aqui entendido, corresponde à "descrição do que idealmente é necessário saber realizar no campo profissional correspondente a determinada qualificação" (SENAI, 2002a, p. 11). Uma das características fundamentais para a definição do perfil profissional é a identificação de "competências profissionais que reúnam todas as capacidades (técnicas, metodológicas, organizativas e sociais) necessárias para um desempenho profissional adequado às exigências do mercado de trabalho" (SENAI, 2002a, p. 12).

A definição de competências profissionais para o exercício de uma determinada função é algo bem complexo. Com o termo competências pretende-se dizer mais do que a formação intelectual ou a experiência do profissional e sua adequação ao tipo de trabalho realizado em cursos on-line. A própria natureza do trabalho está aí representada, identificando ações diferenciadas para a atuação profissional na mesma área em espaços ou situaçōes diversas. É preciso também identificar as tendências futuras no campo de atuação para que se possa oferecer a melhor qualificação profissional e a capacidade de mudanças e adaptação às novas realidades.

No caso específico da atuação do tutor em cursos on-line a distância, procurou-se inicialmente conhecer as características apresentadas pela literatura nacional e internacional sobre o desempenho desse profissional.

A primeira descoberta, neste caminho, diz respeito à variedade de atuações referentes à ação de um "tutor" em cursos on-line. $\mathrm{Na}$ sistematização dessas ações, foram identificados alguns aspectos significativos que nos ajudaram a configurar um campo teórico inicial sobre o seu desempenho e, por conseguinte, suas competências. Destaca-se nesses posicionamentos teóricos a proposta de Gilly Salmon, no livro E-moderating (2003). Esse 
autor identifica competências diferenciadas para o desempenho de um tutor on-line, de acordo com o seu nível de expertise e domínio do processo. Assim, ao tutor recém-contratado, são exigidos comportamentos próximos dos apresentados pelos melhores alunos de cursos on-line. Algumas das condiçôes iniciais, inclusive, estão ligadas à vivência discente em cursos on-line, como, por exemplo: "experiência pessoal como aluno on-line, flexibilidade nas aproximações entre ensinar e aprender e empatia com os desafios de tornar-se um aprendiz on-line" (SALMON, 2003, p. 53). A essas, somam-se novas competências incorporadas pela capacitação contínua e experiência na função e que irão contribuir para a configuração do perfil ideal de um tutor em curso via Internet.

A estrutura proposta por Salmon, nos três níveis de atuação do tutor on-line, serviu de base para a elaboração do Quadro 1. Para a organização do conteúdo, foram sistematizadas as competências encaminhadas por diferentes autores, como Albuquerque (2005), Berge (2005), Coady; Gilhooly; Macmanus; O'Connell (2003), Denis; Watland; Pirotte; Verday (2004), Döding; Mendes; Kovalski (2003), Fuente; Rios Ramírez (2000), García Aretio (1994), Masuda (2003), Primo (2005), Valencia Marthén (2000), e outros... em teses, artigos, livros e publicações impressas e on-line.

\section{Quadro I: Características desejáveis do tutor on-line - nível de recrutamento'}

Características

Desejáveis

A. Entendimento do processo on-line

B. Habilidades técnicas

C. Habilidades para comunicação on-line

D. Expertise no conteúdo

E. Características pessoais

Nível de Recrutamento

Básicas de formação

Experiência pessoal como aluno on-line; flexibilidade nas aproximações entre ensinar e aprender; empatia com os desafios de tornar-se um aprendiz on-line.

Entendimento operacional do uso do software, boa habilidade no teclado, capacidade razoável de leitura na tela e acesso bom e regular à Internet.

Cortês e respeitável na comunicação on-line (escrita), capacidade em usar o tempo de forma apropriada.

Conhecimento e experiência para compartilhar; boa vontade para dar sua contribuição.

Determinação e motivação para tornar-se um tutor on-line.

\section{Capacidades}

Capacidade de construir um ambiente on-line de confiança. Compreender o potencial da aprendizagem on-line e da atuação dos grupos.

Capacidade de apreciar as estruturas básicas de conferências online e o potencial de aprendizagem da Web e da Internet.

Capacidade em escrever mensagens on-line de forma concisa, personalizada e que motivem. Capacidade para criar "presença" e "visibilidade" no ambiente virtual.

Capacidade em incentivar as contribuições dos alunos e conhecimento dos recursos on-line úteis para esse fim.

Capacidade de estabelecer uma identidade como tutor on-line. 
Após a contratação, novas competências devem ser desenvolvidas por meio de capacitação. Algumas dessas competências são apresentadas no quadro 2:

Quadro 2: Características desejáveis do tutor on-line - nível de capacitação²

Características

Desejáveis

A. Entendimento do processo on-line

B. Habilidades técnicas

C. Habilidades para comunicação on-line

D. Expertise no conteúdo

E. Características pessoais
Nível de Capacitação

Desenvolvimento

Ação como facilitador

Habilidade em desenvolver-se e capacitar outros, promovendo discussões, resumindo, desafiando, monitorando o nível de entendimento, dando feedback.

Saber usar características especiais do software para tutoria on-line.

Capacidade em se comprometer com as pessoas, respondendo às mensagens de forma apropriada, tornando-se "visível" apropriadamente, "administrando" as expectativas dos estudantes.

Capacidade em provocar debates colocando questões provocativas. Saber quando intervir e quando voltar atrás.

Capacidade em se adaptar ao novo contexto de ensino, métodos e papéis.
Saber quando controlar os grupos, quando deixar ir, como trazer os não-participantes, saber os passos de uma discussão on-line e como usar o tempo.

Capacidade para usar o software para analisar a contribuição dos alunos, histórico de mensagens, resumos, acessos etc.

Capacidade para interagir e conseguir a interação entre os alunos. Capacidade de, gradualmente, inserir os participantes nas atividades sem gastar uma enorme quantidade de tempo extra.

Possuir condições para avaliar os alunos pelas participações, contribuições e resultados de aprendizagem.

Mostrar sensibilidade para relacionamentos e comunicação on-line.

E, finalmente, após estar atuando como tutor em vários cursos, é esperado que as competências - citadas no quadro 3 abaixo, entre outras - já tenham sido adquiridas.

Quadro 3: Características desejáveis do tutor on-line - nível de desenvolvimento

\section{Características desejáveis}

A. Entendimento do processo on-line

\section{Nível de Desenvolvimento}

Compartilhamento de conhecimento

\section{Criatividade}

Capacidade de usar uma escala de aproximação entre as atividades estruturadas e as discussões e avaliar o sucesso do processo. 
Nível de Desenvolvimento

desejáveis

Compartilhamento de conhecimento

Criatividade

B. Habilidades técnicas

Capacidade de criar links entre Capacidade de usar as facilidades características de outros progra- do software para criar e manipular mas de aprendizagem, introduzir reuniões e atividades e gerar um outros recursos on-line sem desviar/ ambiente de aprendizagem on-line. perder a interação já existente. Capacidade para usar softwares e plataformas alternativas.

C. Habilidades para comunicação on-line

Capacidade de avaliar a diversidade Capacidade para comunicar-se, com sensibilidade cultural; explorar diferenças.

diagnosticar e resolver problemas, usar o humor e resolver conflitos de forma construtiva.

D. Expertise no conteúdo

E. Características pessoais
Saber sobre recursos disponíveis Capacidade de animar reuniões. (por exemplo, na Web) e usá-los Capacidade em dar feedback crianas atividades. tivo e valorizar as idéias dos participantes.

Mostrar uma atitude positiva, Saber como criar e sustentar uma compromissada e entusiasmada comunidade de aprendizagem com o ensino on-line. on-line útil e relevante.

Nem todos os autores fazem a diferenciação entre as competências iniciais, intermediárias e plenas no desempenho da função de tutoria on-line, como são propostas por Salmon (2003). Gutierrez e Prieto (1994), por exemplo, consideram que as funções básicas do tutor estão mais ligadas aos aspectos educacionais do processo e que, neste caso, o tutor deve estar plenamente preocupado em complementar, atualizar, facilitar e, em última instância, possibilitar a mediação pedagógica e, para isso, ele deve possuir uma clara concepção da aprendizagem; estabelecer relações empáticas com seus interlocutores; sentir o alternativo; construir uma forte instância de personalização; dominar bem o conteúdo e facilitar a construção da aprendizagem. Nessa mesma perspectiva, foram identificadas as competências propostas por Henri (1993), para quem os tutores devem exercer o papel de intermediadores da aprendizagem, tornando compatível o ensino com as expectativas dos alunos, adaptando-o às necessidades destes e ajudando-os a resolver problemas que possam surgir durante seus estudos.

García Aretio (1994) já define o tutor como assessor, conselheiro, animador que motiva a aprendizagem e esclarece e resolve as dúvidas e problemas surgidos nos estudos dos alunos e, em alguns casos, avalia a aprendizagem. Para esse autor, as funções da tutoria em cursos a distância se classificam em: função de orientação (centrada fundamentalmente no âmbito da afetividade, das atitudes e emoções), função acadêmica (focaliza o âmbito cognitivo) e função de colaboração e nexo (do tutor para com a instituição central e com os professores responsáveis pelas disciplinas do curso). 
A reunião das diversas contribuições teóricas deu origem a um rol de mais de 200 competências e funções propostas para a função do tutor, em cursos on-line. Foi necessário, então, definir as particularidades dos cursos (tutoriais com apoio, colaborativos, imersivos), suas finalidades (cursos de formação, treinamento ou capacitação), duração (curta, longo ou média duração) e tipo de tecnologia digital predominante (ambientes virtuais, webconferências, tutoriais disponíveis em websites específicos, etc...) para que fosse possível maior aproximação com o perfil profissional desejado.

\section{OS TUTORES E AS PROPOSTAS PARA EAD VIA INTERNET DO SEBRAEINA}

Em paralelo à análise teórica, foi realizado o estudo da documentação disponível sobre os cursos a distância via Internet do SebraelNa. O processo educacional a distância é bem específico e se baseia nos princípios já definidos para os cursos presenciais da instituição e em orientaçõos específicas, de acordo com os processos de ensino desencadeados nos ambientes virtuais. Assim, a pesquisa foi realizada nesta fase pela análise da função dos tutores como é estabelecida nos documentos oficiais do próprio Sebrae e no texto "Orientex composto", elaborado pelos próprios tutores.

A leitura e análise dos documentos definiram a seleção das competências teóricas listadas. Foi criado, assim, o primeiro perfil operacional amplo que serviu de base para todo o restante da pesquisa empírica, com os tutores. Os resultados alcançados ao final subsidiaram o delineamento de uma proposta de treinamento, atualização e formação dos tutores, de acordo com os objetivos institucionais do SebraelNa.

\section{Visões sobre a função do tutor nos documentos do SebraelNa}

Segundo o documento "Direcionamento Estratégico do Sistema Sebrae 2006/2010", o Sistema perseguirá a seguinte Visão de Futuro para 2010:

"As micro e pequenas empresas constituem-se em importante fator de desenvolvimento do País, atuando em ambiente institucional favorável, com alto índice de formalização, competitividade e sustentabilidade" (SEBRAEINA, 2006, p. 15).

O objetivo da atuação dos tutores nos cursos do SebraelNa oferecidos pela Internet é o de colaborar para que este objetivo maior seja alcançado. Neste sentido, seu foco de atuação está diretamente relacionado ao papel educacional do Sebrae, auxiliando na implementação e gestão das diretrizes que visam "promover educação empreendedora e a cultura da cooperação" entre empresários de micro e pequenas empresas, empreendedores e pessoas interessadas, em geral.

Os princípios orientadores desses novos encaminhamentos para os projetos de educação continuada do Sebrae são apresentados com mais detalhes no documento "Referenciais Educacionais do Sebrae" (2006). Esse documento explicita, logo em seu início, que "a partir da definição do novo Direcionamento Estratégico do Sebrae, a 
reinvenção da sua prática educacional tornou-se uma exigência e um desafio, pela necessidade de se superar a visão fragmentada da oferta de programas de capacitação pontuais e, assim, fundamentar o Sistema Sebrae no processo de desenvolvimento de uma estratégia de educação continuada de empreendedores" (2006, p. 7).

Neste sentido, pontua que:

"A Educação a Distância (EAD) é uma das modalidades que reúnem condições ideais para cumprir essas metas, pois sua característica mais marcante é a capacidade de organização do sistema educativo - meios de comunicação, estratégias, tutoria, material para estudo autônomo - de forma a viabilizar ao aprendiz a construção de seus saberes e a autonomia para aprender a conhecer" (2006, p. 10).

$\mathrm{Na}$ correspondência feita entre as três correntes teóricas (cognitivista, humanista e sociocrítica) e os pilares propostos pela Unesco, a proposta educacional do Sebrae funde "as dimensões aprender a conviver e aprender a ser, o que se justifica pela percepção de que, no mundo atual, saber relacionar-se é elemento fundamental tanto para a constituição das identidades pessoais, quanto para o sucesso de qualquer ação empreendedora" (2006, p. 22). Para concretizar, portanto, o processo desencadeado pelo SebraelNa, tendo em vista o oferecimento de programas de educação continuada no modelo teórico-metodológico escolhido, foram definidos procedimentos pedagógicos que consideram um novo paradigma educacional.

De acordo com os pressupostos apresentados no Manual do Tutor de Cursos, "os cursos pela Internet oferecidos pelo SebraelNa se constituem em importantes soluções educacionais que contribuem para difundir cultura empreendedora e melhorar o desempenho das micro e pequenas empresas, diminuindo por conseqüência a sua mortalidade" (2005, p. 3).

Segundo ainda o "Manual do Tutor de Cursos" (2005, p. 4), o:

"projeto de educação a distância pela Internet foi criado para atender a prioridade de disponibilizar educação empreendedora a milhōes e brasileiros. Iniciou em 2001 e tem suas ações baseadas no documento 'Referenciais para uma nova práxis educacional' (SEBRAEINA, 2001). A cada ano, novos cursos são disponibilizados com notória qualidade, conforme resultados de avaliações de reação e diversas pesquisas realizadas".

No momento da pesquisa, eram oferecidos quatro cursos para a comunidade externa ao SebraelNa, a saber:

1 - "Análise e Planejamento Financeiro - APF - cujo objetivo é o de "desenvolver no participante a competência de analisar e projetar estratégias empresariais a partir de informações financeiras".

2 - Aprender a Empreender - destinado a "empreendedores, empresários de pequenos negócios, atuantes nas áreas do comércio, indústria, serviço e agroindústria”, 
que se interessem em interagir "com conceitos iniciais sobre empreendedorismo, mercado e finanças".

3 - Como Vender Mais e Melhor - CVMM - neste curso o participante "aprende a construir um modelo de gestão de vendas para pequenos negócios a partir do planejamento e ação comercial da empresa”.

4 - Iniciando um Pequeno Grande Negócio - IPGN - “o participante tem a oportunidade de aprimorar conhecimentos conceituais, teóricos e instrumentais para o planejamento de um novo negócio. $\mathrm{O}$ aluno poderá organizar suas idéias e recursos, construindo um roteiro (plano de negócios) com os principais aspectos a serem considerados no planejamento e abertura de um negócio. O seu conteúdo está direcionado ao estudo de viabilidade e implantação de um negócio ou revisão daquele já existente, utilizando como suporte a montagem do Plano de Negócio" (2005, p. 3).

Para atender à demanda, sempre crescente, os cursos a distância realizados pelo SebraelNa são "auto-instrucionais complementados por recursos de interatividade, através da construção de uma comunidade de troca de informações e crescimento grupal, chamada comunidade de aprendizagem" (2005, p. 3).

Essas comunidades de aprendizagem, no modelo educacional do SebraelNa, são orientadas por um tutor que atende, em média, a 200 alunos em cada turma do curso. Segundo o Manual, "a atuação da tutoria amplia a perspectiva auto-instrucional dos cursos pela Internet oferecidos pelo SebraelNA, por dinamizar o ambiente de aprendizagem de forma a favorecer a construção coletiva do conhecimento mediante o processo de interatividade que ocorre na chamada comunidade de aprendizagem" (2005, p. 3).

No modelo Sebrae de EAD via Internet, a comunidade virtual de aprendizagem é definida não pelas interaçôes entre as pessoas (participantes e tutores), mas pelo "ambiente composto por diversas ferramentas que propiciam a aprendizagem (comunidade, fórum, chat, mural, tira-dúvidas)". Nesse ambiente, de acordo com o Manual, o papel do tutor é fundamental, "pois a sua função é de ser facilitador/mediador do processo de aprendizagem, estimulando os debates, a construção coletiva do conhecimento, tirando dúvidas de alunos sobre o conteúdo de forma genérica e individual, lançando desafios, motivando os participantes a continuar seus estudos. Enfim, criando os estímulos adequados para o melhor aproveitamento dos alunos" (2005, p. 3).

Os tutores dos quatro cursos do SebraelNa via Internet foram indicados pelos Sebraes estaduais e passaram por capacitação para o exercício da função. A estrutura para o desenvolvimento dos quatro cursos de EAD via Internet é formada por profissionais que ocupam os seguintes papéis: equipe de coordenação central dos cursos; 10 TM (tutores Master) e 114 tutores. Os 10 TM também exercem a função de tutores nos cursos. Todos os TM são responsáveis por cerca de 10 a 12 tutores e realizam a articulação entre esses e a equipe de coordenação. 
O documento "Orientex" (SEBRAEINA, 2005), por ter sido elaborado como um manual prático de apoio à ação dos tutores - Master, apresenta uma listagem de comportamentos que se configuram como o "perfil do(a) tutor(a)". Nele estão incluídas diversas características como, por exemplo: [...] equilíbrio emocional; conhecimento técnico da ferramenta; [...] saber responder dúvidas de forma pertinente, clara e objetiva; [...] ter interesse no desenvolvimento de sua capacidade técnica e pedagógica; [...] comprometer-se com os referenciais educacionais e [...] ser educador dentro do conceito do "referencial educacional do Sebrae", promovendo o aprender a conhecer, aprender a fazer, aprender a conviver e aprender a ser (2005, p. 5).

O "Orientex" também apresenta algumas atribuições dos tutores em exercício em cursos via Internet. Algumas dessas atribuições são:

“... promover a integração e participação entre os alunos na comunidade/Fórum... comunicarse com linguagem apropriada e adequada para cada um dos diversos grupos da turma (abaixo, dentro e acima do ideal) [...] realizar as atividades de tutoria no ambiente do curso, acessando-o, necessariamente todos os dias úteis e facultativamente em finais de semana e feriados [...] estabelecer um ambiente propício para o aprendizado coerente com os princípios dos referenciais educacionais do Sebrae..." (2005, p. 4).

A compatibilização entre as competências levantadas na teoria e as atribuições já previstas pelos tutores levou-nos ao levantamento de um perfil profissional que não se restringiu aos aspectos teóricos, técnicos e pedagógicos ligados à função. Foram identificadas também habilidades de interação e comunicação on-line, tomada de decisões, organização do trabalho e outros comportamentos necessários ao pleno desempenho do tutor on-line. Ao final, foi estabelecida uma listagem com 175 itens ligados às competências do tutor on-line. Esses itens foram analisados tendo por base o objetivo geral da ação de um tutor de cursos pela Internet, ou seja, acompanhar o desenvolvimento do curso pela Internet e garantir a qualidade da interação entre os participantes, assim como um maior nível de aprendizado.

A análise crítica dos itens levantados deu origem à concentração das funções em grandes unidades de competência, que foram chamadas de "domínios". Foram assim definidos seis domínios de atuação, nos quais se concentram as competências, com um nível maior de detalhamento. Esses "domínios" são os seguintes:

\section{Condiçóes pessoais.}

Englobam as características pessoais que facilitam a atuação como tutor na Internet.

\section{Envolvimento com a organização.}

Atitudes pessoais de comprometimento com a proposta de EAD e com a organização.

\section{Domínio do conteúdo.}

Conhecimentos específicos relacionados aos conteúdos dos cursos. 


\section{Conhecimentos pedagógicos em EAD.}

Conhecimentos específicos sobre a proposta pedagógica dos cursos.

\section{Conhecimentos técnicos.}

Conhecimentos específicos ligados à fluência no ambiente virtual dos cursos.

\section{Capacidade de interação e comunicação.}

Habilidades e atitudes ligadas à capacidade de interação e comunicação on-line.

Todos os itens listados inicialmente foram dispostos nos seis domínios estabelecidos. Nas rodadas de discussão realizadas virtualmente com dirigentes e tutores designados pelo SebraelNa, foram alteradas, integradas ou excluídas algumas das competências inicialmente levantadas. Em sucessivas rodadas, foram sendo definidas com maior detalhamento as categorias e as competências que correspondiam às expectativas ideais de atuação de um tutor on-line do Sebrae. Todas as competências foram discutidas não apenas em relação à sua pertinência como ação do tutor (existente ou desejável), mas também na redação clara e precisa do desempenho esperado. Ao final, foram identificadas e validadas 83 competências distribuídas por seis domínios, conforme mostram os quadros 4 a 9 a seguir.

\section{Perfil do Tutor de EAD via Internet do SebraelNa}

\section{Quadro 4: A. Competências pessoais. ${ }^{4}$}

\section{Competências}

I. Ter atenção aos detalhes do curso.

2. Estar atento aos movimentos da turma.

3. Ser paciente. Não se irritar com facilidade.

4. Agir de maneira paciente com os participantes.

5. Ser crítico.

6. Gostar do que faz como tutor.

7. Ser persistente. Não desistir fácil diante das dificuldades.

8. Ser entusiasta.

9. Ser criativo.

10. Ser dinâmico.

II. Ser pró-ativo. Tentar se antecipar aos problemas e dificuldades.

12. Ser responsável em relação às atividades que realiza.

13. Ser assertivo. As soluções que encontra são adequadas (ou pertinentes) aos problemas.

14. Ser empático. Consegue se colocar no lugar dos participantes. 


\section{Competências}

16. Usar o tempo de tutoria de forma apropriada.

17. Comunicar-se com participantes e os TM sem usar palavras de baixo calão e ofensivas.

18. Ter bom domínio da linguagem escrita.

19. Ter capacidade para conduzir os debates.

20. Ter capacidade para animar a comunidade de participantes do curso.

21. Gostar de enfrentar os desafios postos em cada nova turma do curso.

22. Compartilhar com os participantes os seus conhecimentos e experiências em relação aos temas do curso.

23. Ter dedicação e comprometimento com o trabalho e com as pessoas envolvidas.

24. Agir dentro das normas éticas estabelecidas para os cursos em EAD do Sebrae.

25. Ter ética profissional.

26. Cumprir os prazos das tarefas pertinentes ao seu trabalho na tutoria do curso.

27. Realizar ações para sua capacitação e aperfeiçoamento técnico e educacional como tutor.

28. Ter motivação para ser tutor on-line.

29. Procurar criar sua própria identidade como tutor.

30. Ter consciência da importância do seu papel como agente de mudanças.

Quadro 5: B. Competências ligadas ao processo de educação do Sebrae. ${ }^{5}$

\section{Competências}

I. Conhecer a metodologia de educação a distância do Sebrae.

2. Identificar-se com a filosofia de educação a distância do Sebrae.

3. Conhecer a realidade do público-alvo atendido pelo Sebrae.

4. Elaborar o planejamento de tutoria para a turma que se inicia.

5. Identificar-se como educador do Sebrae, promovendo o saber conhecer, saber ser e conviver e saber fazer.

6. Conhecer o sistema de avaliação do Sebrae para EAD.

7. Participar dos cursos e dos eventos de educação continuada promovidos pelo Sebrae.

8. Colaborar com a sala de tutores e com os TM.

\section{Quadro 6: C. Competências ligadas aos conteúdos dos cursos. ${ }^{6}$}

\section{Competências}

I. Possuir domínio do conteúdo do curso em que exerce tutoria.

2. Demonstrar capacidade lógica de análise e síntese do conteúdo do curso.

3. Ser capaz de interpretar os textos escritos do curso. 


\section{Quadro 6: continuação}

\section{Competências}

4. Conhecer formas diferenciadas de estudo dos conteúdos do curso em que exerce tutoria.

5. Conhecer a proposta educacional do curso (objetivos, conteúdos, método, atividades...).

6. Conhecer alternativas (bibliografias, cursos, etc), principalmente do SebraelNA, que possam auxiliar os participantes no aprofundamento dos conteúdos do curso.

Quadro 7: D. Competências relativas aos conhecimentos educacionais em EAD.

\section{Competências}

I. Analisar previamente a proposta do curso para poder planejar as ações como tutor.

2. Planejar atividades diferenciadas ligadas aos conteúdos do curso.

3. Esclarecer os participantes a respeito das competências a serem desenvolvidas no curso.

4. Conduzir os debates nos fóruns, colocando questões que façam sentido para os alunos.

5. Usar os recursos disponíveis no ambiente virtual para dinamizar as atividades do curso.

6. Apresentar alternativas para os participantes visando aprofundar os conteúdos do curso.

Quadro 8: E. Competências relativas aos conhecimentos técnicos em EAD via Internet. ${ }^{8}$

\section{Competências}

I. Conhecer as formas de acesso à Internet.

2. Conhecer facilidades na Internet (sites de busca, sites de pesquisa, acesso a textos e revistas especializadas, etc...) que podem auxiliar os participantes na compreensão dos conteúdos.

3. Ser hábil no uso do teclado (velocidade e correção na escrita).

4. Saber usar o editor de texto e a planilha de cálculo.

5. Saber usar acessórios e periféricos básicos do computador, bem como os mecanismos de comunicação pela Internet (MSN, Skype e compatíveis).

6. Conseguir oferecer suporte técnico aos participantes quando solicitam.

7. Saber a quem encaminhar os problemas técnicos apresentados pelos participantes, quando não consegue resolver.

8. Conhecer as ferramentas e possibilidades do ambiente educacional virtual do curso.

Quadro 9: F. Competências ligadas à comunicação e interação on-line ?.

\section{Competências}

I. Saber escrever corretamente em Português.

2. Procurar utilizar linguagem escrita correta, sem o uso de gírias.

3. Ser capaz de estabelecer comunicação oral e escrita significativa.

4. Ser cortês e respeitável. Conseguir manter uma postura simpática e de respeito na comunicação escrita.

5. Escrever mensagens de forma concisa e personalizada.

6. Usar linguagem profissional e adequada ao nível do curso. 


\section{Quadro 9: continuação}

\section{Competências}

7. Ser capaz de responder dúvidas de forma pertinente, clara e objetiva.

8. Ter facilidade para se relacionar, comunicar e conversar pela Internet.

9. Como tutor, saber explorar idéias, desenvolver argumentos, promover boas discussões, encerrar discussões improdutivas.

10. Saber controlar os grupos: quando deixar a comunicação mais livre e quando ser mais diretivo.

II. Saber como trazer os não-participantes de volta ao ambiente do curso.

12. Como tutor, conseguir criar "presença" e "visibilidade" no ambiente virtual.

13. Ser atencioso com participantes e colegas tutores.

14. Incentivar os participantes a apresentarem suas contribuições.

15. Evitar tomar atitudes autoritárias ou excessivamente permissivas.

16. Desenvolver formas de comunicação com os participantes para evitar que eles se sintam sós.

17. Interagir com os participantes por e-mail e demais ferramentas on-line disponíveis.

18. Estabelecer um ambiente propício para o aprendizado e a troca de informações entre todos.

19. Conseguir criar e manter com os participantes uma comunidade on-line útil e relevante.

20. Saber trabalhar em equipe.

21. Conseguir administrar os conflitos que ocorrem nos cursos.

22. Saber quando deve intervir nos conflitos e quando é melhor voltar atrás.

23. Não ter problemas nas relações com os demais membros da equipe de tutores dos cursos e a equipe EAD.

24. Respeitar as idéias apresentadas por outros tutores e pela equipe EAD.

25. Manter um fluxo de comunicação com o TM.

O Perfil do Tutor de EAD via Internet do SebraelNa foi, assim, composto por 83 competências. Dessas, 30 competências estão ligadas a atitudes e aspectos pessoais de comportamento. Em outra categoria, foram identificadas oito competências básicas vinculadas às especificidades do processo educacional do Sebrae. Em relação ao domínio de conteúdos dos cursos em que atuam, foram validadas seis competências gerais. Foram seis, também, as competências validadas pelos tutores relativas aos conhecimentos educacionais fundamentais para o exercício da tutoria on-line. Já os conhecimentos técnicos tiveram validadas oito competências necessárias para a ação do tutor nos cursos. A segunda categoria com maior número de competências validadas foi a relativa às condições de comunicação e interação dos tutores em cursos on-line. 


\section{CONSIDERAÇÕES SOBRE POSSIBILIDADES DE EDUCAÇÃO CONTINUADA PARA OS TUTORES, DE ACORDO COM OS RESULTADOS DA PESQUISA}

Ao final da pesquisa foram definidas as competências e realizadas avaliaçóes (autoavaliação e avaliação do tutor master) do desempenho de todos os tutores em exercício nos cursos em EAD via Internet do SebraelNa. Os seus resultados orientaram a elaboração de considerações e possibilidades de desenvolvimento de projetos de educação continuada para os tutores, apresentadas a seguir.

O ponto de partida para a formação de tutores em um processo de educação continuada é a própria visão de futuro do Sebrae, que tem como foco de atuação a prestação de serviços ao empreendedor, empresário das micro e pequenas empresas, garantindo a sua atuação "em ambiente institucional favorável, com alto índice de formalização, competitividade e sustentabilidade".

Para garantir que esses objetivos sejam alcançados, a aprendizagem desse empreendedor, que é o participante dos cursos de EAD via Internet do Sebrae, precisa ser da mais alta qualidade. Para isto, não basta a disponibilização dos conteúdos e nem a respostas eventuais a dúvidas que possam encaminhar aos responsáveis pelos cursos. É preciso mais. É preciso garantir que a atuação dos tutores seja a de mais alto nível profissional, para que os processos de interação com os participantes nos cursos garantam o aprendizado e a aplicação do aprendido nas suas pequenas e microempresas.

O tutor, portanto, como mediador entre o Sebrae e os participantes, torna-se elo fundamental para a viabilização das diretrizes e metas da instituição que garantam o sucesso do segundo em seus empreendimentos. Sua formação e acompanhamento devem ser considerados estratégicos, uma vez que configuram, nas suas ações, a performance da instituição.

Consideram-se, nesta proposta, dois aspectos estratégicos e de primordial importância. O primeiro, diz respeito ao próprio formato fechado dos cursos. Há que se pensar na possibilidade de novos cursos a distância com formatos mais abertos e com possibilidades maiores de participação e interação entre tutores e alunos, para o atendimento diferenciado de participantes que desejam aprender conteúdos específicos. Um outro aspecto é a natural tendência de ampliação da oferta de cursos e o aproveitamento dos tutores bem sucedidos como TM nessas novas ofertas.

Assim, o modelo do curso de formação aqui proposto envolve cinco momentos que podem ser incorporados de forma completa (evidenciando um programa de formação de tutores), parcial (como um programa de capacitação) ou pontual (como um programa de atualização).

O desenho desta proposta considera tanto os atuais tutores como os novos tutores, recém-contratados, de acordo com a ampliação da oferta de cursos a distância, e a possibilidade de promoção dos atuais tutores, de acordo com o seu aproveitamento e 
desempenho nos cursos e nas tutorias on-line. A previsão, de acordo com a realidade do trabalho do tutor, é que todas as atividades educacionais propostas sejam feitas a distância, via Internet, com encontros presenciais opcionais ao final de cada semestre letivo.

Os treinamentos emergenciais - para sanar problemas específicos ou informar sobre novos procedimentos - podem ser realizados em cursos ou seminários de curta duração (quatro a seis semanas no máximo, com 20 ou 30 horas on-line), segundo as propostas cooperativas e colaborativas de aprendizagem. Esses cursos teriam como eixos orientadores os princípios definidos pelo programa EAD do Sebrae (saber conhecer, saber ser/conviver e saber fazer) e seriam desenvolvidos a partir da análise de casos ligados à tutoria na Internet. Em todos esses cursos, os alunos devem ter oportunidades para o exercício de competências formativas ligadas ao seu desempenho pessoal e profissional (criticidade, criatividade, assertividade etc.).

Baseado no modelo de cinco estágios apresentado por Gilly Salmon (2003) para formação de tutores, desenvolvemos a presente proposta em que apresentamos um Modelo de Formação Continuada de Tutores, de acordo com as características e competências relacionadas à função dos tutores nos curso EAD via Internet do SebraelNa.

Para o desenvolvimento da proposta, consideramos ainda, assim como Delors (1998, p. 90), que:

"a educação deve organizar-se em torno de quatro aprendizagens fundamentais, que, ao longo de toda a vida, serão de algum modo para cada indivíduo os pilares do conhecimento: aprender a conhecer, isto é, adquirir os instrumentos da compreensão; aprender a fazer, para poder agir sobre o meio envolvente; aprender a viver juntos, a fim de participar e cooperar com os outros em todas as atividades humanas; finalmente aprender a ser, via essencial que integra as três precedentes. É claro que estas quatro vias do saber constituem apenas uma, dado que existem entre elas múltiplos pontos de contato, de relacionamento e de permuta". ${ }^{10}$

E acrescentamos um "quinto pilar": "Aprender a criar", ou seja, a usar todas as aprendizagens anteriores para avançar no conhecimento, inovar e se abrir para mudanças. Essa formação proposta inclui "...uma intricada e complexa interação entre processos neuronais, cognitivos, motivacionais, afetivos e sociais" (SALMON, 2005) que encaminham a pessoa para uma nova postura diante da função de tutor, diante do conhecimento e do aprendizado on-line.

Nessa proposta pretende-se também que os tutores possam sentir que formam uma "webness" (KERCKHOVE, 2002), ou seja, uma comunidade de pessoas, conectadas via Internet, que aprendem e avançam juntas no conhecimento, preocupadas com a sua aprendizagem e com a aprendizagem de todo o grupo. $\mathrm{O}$ fato de as atividades serem majoritariamente realizadas via Internet é considerado fundamental para garantir aos tutores a vivência como "alunos a distância", o que lhes garantirá maior empatia com os seus tutorados nos cursos on-line do SebraelNa em que já exercem ou irão exercer tutorias. 


\section{ESTRUTURA E ORGANIZAÇÃO DO MODELO}

O modelo de formação continuada de tutores para EAD on-line do SebraelNa prevê seis etapas seqüenciadas de desenvolvimento. Ele pode ser cumprido integralmente por um tutor iniciante ou pode haver a entrada de tutores mais experientes, em qualquer uma das etapas previstas no modelo. A sequiência foi planejada tendo por base a formação plena para a tutoria de profissionais novos, ou seja, sem experiências anteriores em tutorias on-line.

Presume-se que cada etapa tenha a duração de cerca de oito semanas seguidas (on-line) e cinco horas de dedicação semanal, perfazendo um total de 40 horas. Ao final dos cinco etapas teremos um total de 200 horas de atividades on-line. As etapas estão divididas em módulos e podem ser trabalhadas isoladamente ou em novas articulaçôes, conforme o interesse dos coordenadores dos cursos ou a demanda de um grupo de tutores mais experientes, considerado significativamente viável pela Coordenaçãoo (por exemplo, 10 ou mais tutores que desejam estudar apenas o tema de um módulo específico). As atividades on-line podem ser complementadas por atividades presenciais ao final de cada etapa (bimestrais). As atividades presenciais servirão para apresentação oral de trabalhos e avaliações e terão a duração de oito horas (um dia: manhã e tarde). O desenvolvimento de todas as atividades presenciais previstas corresponde a um total de 40 horas de atividades.

Prevê-se que em cada etapa o tutor iniciante (obrigatoriamente), ou mesmo o tutor experiente (opcionalmente), realize atividades de estágio junto aos cursos do SebraelNa via Internet. Essas atividades também obedecem a um processo gradativo de interação e desempenho como tutor. Iniciam-se como estágios de observação e participação orientada (20 horas - etapas de um a quatro) e correspondem ao tempo integral (tutoria plena) da etapa cinco (quarenta horas). Na sexta etapa o estágio pode ser orientado para a apresentação pelo tutor de um projeto para o desenvolvimento de um novo curso a distância a ser ofertado pelo Sebrael $\mathrm{Na}$ (caso haja interesse da instituição e dependendo da qualidade do projeto) para o qual terá o tempo de 40 horas. São previstas, dessa forma, 100 horas de estágio e mais 40 horas de desenvolvimento de projeto de curso.

A avaliação e progressão dos tutores pelas diferentes etapas do modelo prevê a seleção dos que obtiveram os maiores índices de aproveitamento na etapa anterior. Cada uma das etapas terá progressivamente um número menor de vagas.

Os pré-requisitos necessários aos participantes para o início desse processo de formação são o conhecimento e a experiência em conteúdos específicos e no processo educacional do Sebrae. Além disso, deve ser exigida fluência tecnológica e o acesso individual ao ambiente virtual do curso, preferencialmente em banda larga, para o desenvolvimento das atividades previstas.

O aprimoramento da fluência tecnológica, de acordo com os objetivos da tutoria on-line, constitui um dos objetivos da etapa inicial. Prevê-se também o início do desenvolvimento 
de habilidades de comunicação escrita, que serão exigidas ao longo de todo o processo de formação, cada vez com um nível maior de exigência. Na etapa 1 (um) também é previsto o pleno domínio dos pressupostos e princípios do Programa para EAD via Internet do SebraelNa, assim como o conhecimento das características gerais de cursos a distância on-line, no atual momento de desenvolvimento tecnológico.

A segunda etapa prevê a construção e definição da identidade do tutor do Sebrae, o desenvolvimento de habilidades de interação e comunicação significativa com os alunos e a conscientização da importância de seu papel na construção do conhecimento dos alunos.

A terceira etapa prevê o aprofundamento dos participantes nos temas e conteúdos específicos em que exercem tutorias e a apresentação de informações relevantes aos demais tutores sobre as formas como exploram essas temáticas. As trocas de informaçôes e experiências entre os participantes são estimuladas em todos os estágios e serão particularmente decisivas neste momento, quando se prevê o alcance de processos avançados de cooperação entre todos (elaboração de textos coletivos, uso de ferramentas de cooperação etc.).

A quarta etapa é dedicada à gestão do processo de tutoria e ao planejamento de atividades ligadas aos cursos em que atuam. A interação neste momento deve ser mais colaborativa, com o estabelecimento de metas e objetivos comuns. A quinta etapa é o momento de avançar no conhecimento e propor novas formas de ensino e de aproveitamento dos ambientes interativos da Internet para alcançar maiores e melhores condições de aprendizagem e as competências ligadas a elas. A sexta etapa prevista no Modelo encerra esta progressão e abre caminho para novos e diferenciados desempenhos de tutoria. É quando os mais bem sucedidos tutores ampliam os seus conhecimentos sobre o processo de criação e planejamento de um curso on-line, nos moldes dos cursos oferecidos pelo SebraelNa. Objetiva lhes oferecer a possibilidade de criação e planejamento de cursos on-line.

Em cada etapa os participantes devem desenvolver gradativamente habilidades cada vez mais complexas ligadas ao uso de programas e softwares específicos, ambientes e ferramentas on-line. $\mathrm{O}$ grau de interação entre os participantes também será ampliado gradualmente até alcançar o processo cultural de formação plena de uma comunidade colaborativa de aprendizagem. As atividades e estratégias que ocorrerão em cada etapa serão oportunidades para que, além dos objetivos específicos delineados em cada momento, as habilidades e atitudes ligadas à fluência tecnológica, interação e colaboração on-line, comunicação oral (som) escrita (texto) e digital (hipertextual) possam ocorrer. Dessa forma, pretende-se alcançar objetivos de formação plena dos tutores, ligados aos princípios e processos que norteiam todo o programa de EAD do Sebrae.

Em síntese, o Modelo ora proposto tem 400 horas de cargas horárias, distribuídas em seis etapas de cerca de 40 horas cada uma, obedecendo à seguinte estrutura: 
1.início de um processo de formação em tutoria em EAD;

2. construção da identidade do tutor em EAD;

3. exploração dos conteúdos dos cursos;

4. planejamento e gestão de tutoria nos cursos a distância;

5. acompanhamento e avaliação de cursos a distância, e

6. criação e planejamento de cursos a distância.

A cada uma dessas etapas corresponde um tipo diferenciado de estágio. Esses estágios irão desde a simples observação e acompanhamento de um tutor até à tutoria orientada e tutoria plena.

\section{CONCLUSÕES}

A definição do perfil de um tutor de EAD é algo complexo e diferenciado. Necessariamente precisa ser contextualizado. As especificidades da organização, o tipo de proposta educacional que desenvolve, os tipos de cursos que oferece e as tecnologias envolvidas são alguns dos aspectos que irão orientar a definição dos papéis a serem desempenhados pelos tutores nos cursos on-line. $\mathrm{O}$ perfil aqui levantado reflete a visão de uma instituição que se mantém preocupada com o alto nível de qualidade das oportunidades educacionais oferecidas. A definição das competências, a avaliação dos tutores em exercício e a proposta de formação continuada para esses profissionais representam a preocupação com a permanente melhoria da equipe para que seus membros possam atuar com o mais alto nível de qualidade educacional, promovendo a "educação empreendedora e a cultura da cooperação" entre empresários de micro e pequenas empresas, empreendedores e pessoas interessadas, em geral.

\section{Notas}

1. Quadro elaborado pela autora da pesquisa a partir da estrutura proposta por Salmon (2003) e composta pela sistematização de competências desejáveis encontradas nos diversos autores pesquisados.

2. Quadro elaborado pela autora da pesquisa a partir da estrutura proposta por Salmon (2003) e composta pela sistematização de competências desejáveis encontradas nos diversos autores pesquisados.

3. Quadro elaborado pela autora da pesquisa a partir da estrutura proposta por Salmon (2003) e composta pela sistematização de competências desejáveis encontradas nos diversos autores pesquisados.

4. Quadro construído pela pesquisadora com as competências validadas pelos tutores do SebraelNA.

5. Quadro construído pela pesquisadora com as competências validadas pelos tutores do SebraelNA. 
6. Quadro construído pela pesquisadora com as competências validadas pelos tutores do SebraelNA.

7. Quadro construído pela pesquisadora com as competências validadas pelos tutores do SebraelNA.

8. Quadro construído pela pesquisadora com as competências validadas pelos tutores do SebraelNA.

9. Quadro construído pela pesquisadora com as competências validadas pelos tutores do SebraelNA.

10. DELORS, Jacques (Org.) et al. Educação: um tesouro a descobrir; relatório para a Unesco da Comissão Internacional sobre Educação para o sécu1o XXI. São Paulo: Cortez; Brasília: MEC: Unesco, 1998. Cap. 4.

\section{Referências}

ALBUQUERQUE, Luciete Basto de. Formação contínua de tutores no/para o ensino a distância: representaçôes dos tutores e professores-especialistas do curso de pedagogia a distância da UFMT. 2005. Tese (doutorado), Faculdade de Educação. Universidade de São Paulo. São Paulo.

BERGE, Zane. The Role of the Online Instructor/Facilitator. Disponível em: <www.emoderators. com/moderators/teach_online.html>. Acessos em: out./dez. 2005.

BRASIL. Ministério da Educação e Cultura. Educação profissional: referenciais curriculares nacionais da educação profissional de nível técnico. Brasília, 2000.

COADY, Jenny; GILHOOLY, Dolores; MACMANUS, Mabel; O’CONNELL, Mary. E-Moderating and E-tivities. Waterford Institute of Technology, Cork Road, Waterford, Ireland. Disponível em: <www.ilta.net/EdTech2003/papers/oconnelleModerating.doc>. Acessos em: out./dez. 2005.

DELORS, Jacques (Org.) et al. Educação: um tesouro a descobrir; relatório para a Unesco da Comissão Internacional sobre Educação para o sécu1o XXI. São Paulo: Cortez; Brasília: MEC: Unesco, 1998.

DENIS, Brigitte; WATLAND, Philip; PIROTTE, Sébastien; VERDAY, Nathalie. Roles and Competencies of the e-Tutor. Networked Learning Conference 2004. Lancaster University. UK. Disponível em: <www.shef.ac.uk/nlc2004/Proceedings/ Symposia/Symposium6/Denis_et_al.htm>. Acessos em: out./dez. 2005.

DÖDING, Magrit; MENDES, Rosana; KOVALSKI, Selma. O papel do monitor em cursos a distancia através da Internet. VII CREAD. Congresso de Educação a distância. Mercosur. Florianópolis. 2003. Disponível em: <www.didatix.com.br/componentes/utilitarios/ download.jsp? ildArquivo= 3\&s Arquivo=CREAD_Selma.doc $>$. Acessos em: out./dez. 2005.

FUENTE, Margarita de la; RIOS RAMÍREZ, José. Gonzalo. La tutoria, una estrategia para mejorar la calidad de la educación superior. In: Programas Institucionales de Tutorías. Serie Investigaciones, ANUIES, 2000. Disponivel em: <www.uach.mx/universitario/16/tutoria.htm>. Acessos em: out./dez. 2005.

GARCÍA ARETIO, Lorenzo. Educación permanente: educación a distancia hoy. Madrid: Universidad Nacional de Educación a Distancia. Los Herreros, 1994.

GUTIERREZ, Francisco; PRIETO, Daniel. A mediação pedagógica. Campinas: Papirus, 1994. HERNÁNDEZ GUTIÉRREZ, Misael; RUIZ VILLAR, Maria Cristina; VALENCIA MARTHÉN, Ramón. La tutoria academica: una estrategia para la adquisición de valores. Universidad Veracruzana, 2000. Disponível em: <www.uv.mx/iiesca/revista2000/tutoria.htm>. Acessos em: dez. 2005. 
MASUDA, Masako Oya. Sistema de tutoria nos cursos do centro de educação superior a distância do estado do Rio de Janeiro. In: Salto para o Futuro. Educação a Distância na universidade do século XXI. Boletim 2003. Disponível em: <www.tvebrasil.com.br/salto/>. Acesso em: out./dez. 2005.

PRIMO, Lane. "Avaliação de competências em cursos de ead: relato de experiência”. Boletim Técnico do SENAC. Disponível em: <www.senac.br/informativo/BTS/313/boltec313f.html>. Acesso em: dez. 2005.

SALMON, Gilly. All things in Moderation. Disponível em: <http://www.atimod.com/>. Acesso em: dez. 2005.

. E-moderating: The Key to Teaching and Learning Online (2nd Edition). New York: Routledge/Falmer. 2003.

SEBRAE. Educação Sebrae pela Internet. Manual do Tutor. Versão preliminar. Documento em PDF. Ago. 2005.

SEBRAE. Referenciais educacionais do Sebrae. Documento em PDF. 2006.

Referenciais para uma nova práxis educacional. 2. ed. Documento digitado. Versão em PDF. Nov. 2001.

Conselho Deliberativo Nacional. Direcionamento Estratégico do Sistema Sebrae. 2006 / 2010. Texto digitado. Versão em PDF.

. Equipe Sebrae de EAD pela internet. "Orientex Composto". 2005.

SEDUC-MG, Projeto Veredas. Formação Superior de Professores. Proposta pedagógica. Disponível em: <www.veredas.mg.gov.br>. Acessos em: out./dez. 2005.

SENAI, DN. Metodologia [de] avaliação e certificação de competências. Brasília. 2002.

, DN. Metodologia [para] elaboração de perfis profissionais. Brasília. 2002.

TARDIF, M. Saberes docentes e formação profissional. 3. ed. Trad: Francisco Pereira. Petrópolis: Vozes, 2002.

UNED. Reglamento Del profesor-tutor de la Uned, 13 de Julio de 1990. In: Boletín Informativo de Profesores. Normativas sobre el profesor-tutor. Uned, Madrid: Impresos Y Revistas, 1994. 


\section{Profile of the tutor of Internet courses of Sebrae}

\section{Abstract}

This text describes a few moments of the research done with the tutors who work in the courses by Internet given by Sebrae. To start with, a first moment of the research is presented, that is when the profile of the tutor and his competencies were defined, based on theoretical surveys, followed by consultations with those professionals who work as coordinators and as tutors for the courses given online by Sebrae. Then a document on the results of this survey was produced. This document was distributed and analyzed by the totality of the tutors who work with the four on-line courses offered by Sebrae. Based on the responses of the tutors, a model of continuing education of tutors was proposed so they can work better with on-line courses.

Keywords: Sebrae. Distance Education. On-line Courses. Tutor. Competencies. Continuing Education.

\section{Le profile du tuteur des cours par l'Internet offerts par Sebrae} Résumé

Ce texte relate quelques moments de la recherche réalisée avec les tuteurs qui travaillent dans les cours via Internet du Sebrae. Dès le départ, le premier moment de la recherche est présenté, c'est-à-dire quand le profile du tuteur et de ses compétences ont été définies, à partir de données théoriques et suivit de consultations avec les professionnels qui travaillent dans la coordination et le tuteurage des cours par Internet du Sebrae. Ensuite, un document sur les résultats de ce relevé a été produit. Ce document a été distribué et analysé par l'ensemble des tuteurs qui travaillent dans les quatre cours on-line offerts par le Sebrae. À partir de l'analyse des réponses des tuteurs, un modèle de formation continue a été proposé pour les tuteurs qui travaillent dans les cours on-line.

Mots clefs : Sebrae. Éducation à Distance. Cours On-line. Tuteur. Compétences. Formation Continue.

\section{Perfil de tutor de cursos por la Internet: el caso del Sebrae}

\section{Resumen}

Este texto relata algunos momentos de la investigación hecha con los tutores que actúan en los cursos vía Internet del Sebrae. Inicialmente, se presenta el primer momento de la investigación, cuando fue definido el perfil del tutor y sus competencias, a partir de levantamientos teóricos y seguidas consultas a los profesionales que actuan en la coordinación y en las tutorias de los cursos online del Sebrae. Luego, un documento sobre los resultados de esta investigación se elaboró. Este documento fue distribuido y analizado por la totalidad de los tutores que trabajan con los cuatro cursos en línea ofrecidos por Sebrae. Basándose en las respuestas de los tutores, un modelo de educación continua de los tutores se propuso para que puedan trabajar mejor con los cursos en línea.

Palabras-clave: Sebrae. Educación a Distancia. Cursos en línea. Tutor. Competencias. Educación Continua.

Recebida I ${ }^{\mathrm{a}}$ versão em: | 3.02 .2007

Aceita $2^{\mathrm{a}}$ versão em: 12.07.2007 
